\title{
The influence of operational parameters and feed preparation in a convective batch ribbon powder mixer
}

This article was published in the following Dove Press journal:

Drug Design, Development and Therapy

II November 201 I

Number of times this article has been viewed

\author{
Sin Tung Yeow \\ Asnawi Shahar \\ Norashikin Abdul Aziz \\ Mohd Shamsul Anuar \\ Yus Aniza Yusof \\ Farah Saleena Taip \\ Department of Process and Food \\ Engineering, Faculty of Engineering, \\ Universiti Putra Malaysia, Selangor, \\ Malaysia
}

Purpose: To investigate the effect of feed preparation characteristics and operational parameters on mixing homogeneity in a convective batch ribbon mixer.

Methods: Lactose 100M, lactose 200M, ascorbic acid, and zinc oxide powders were used for the mixing study. Operational parameters studied were rotational speed and mixing time. The feed preparations studied were the use of preblending and the particle size of the feed materials. The blends of ascorbic acid, zinc oxide, and lactose were prepared with preblending and without preblending, prior to mixing at different blender rotation speeds and mixing times. Chemical tests were performed to measure the homogeneity of the ascorbic acid in the model mixture.

Results: With preblending, a mixture with lactose $200 \mathrm{M}$ achieved the required homogeneity in a shorter period of time at a lower rotational speed.

Conclusion: The results indicated that the homogeneity of the mixtures was influenced by the blender rotation speed and mixing time. Better mixing can be obtained with higher rotation speeds and longer mixing time. It was also observed that preblending and smaller feed particle size achieved the required homogeneity in a shorter period of time at a lower rotational speed. These results illustrate that using binders with a smaller particle size and a preblending technique improves the mixing process in a convective batch ribbon powder mixer. However, prolonged periods of high-speed mixing will lead to mixture segregation.

Keywords: powder blending, ascorbic acid, rotational speed, particle size, preblending

\section{Introduction}

Homogeneity of powder mixing is important in the pharmaceutical industry. This is to ensure uniformity of the drug ingredients and hence the efficacy of the medicinal product. Obtaining the best mixing procedure is one of the greatest challenges faced by the industry. This is because mixing performance can be influenced by powder properties, equipment design, processing conditions, and operator methodology.

Most published work has focused on operating conditions such as impeller rotational speed, mixer inclination angle, and flow rate in continuous mixing process. ${ }^{1-4}$ However, only a few types of mixer designs have been examined in the literature. In industrial practice, batch mixing is commonly used to produce large-scale output of new product formulations. ${ }^{5}$ Continuous mixing is commonly applied in large industries and to established production procedures. There is an increased demand for continuous mixing due to its short processing time, large output, and ease of handling as the need for labor is minimal. However, there are some drawbacks to this type of system, as the factors influencing the mixing are more difficult to control. Moreover, homogeneity of the mixture is more difficult to achieve and the capital required to set up a complete
Correspondence: Norashikin Abdul Aziz Department of Process and Food Engineering, Faculty of Engineering, Universiti Putra Malaysia, 43400 UPM Serdang, Selangor, Malaysia

Tel +03 89464302

Fax +038946 4440

Email shekeen@eng.upm.edu.my 


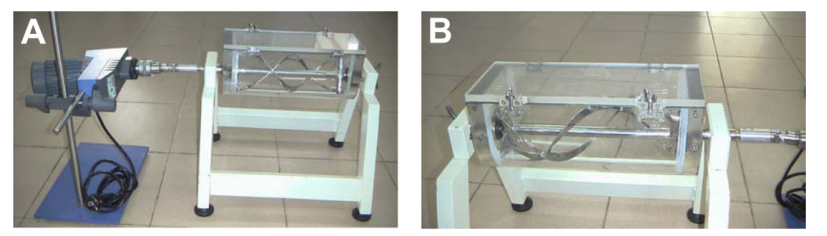

Figure I Photographs of the batch ribbon mixer. (A) The complete mixer and (B) a close-up of U-shaped container.

processing system with a continuous mixer is much higher than for batch mixing. ${ }^{5}$

Batch ribbon mixers are widely used in the pharmaceutical industry. Many factors can affect their mixing homogeneity and most of the literature has investigated only selected factors. Côté and Abatzoglou, ${ }^{6}$ for example, reported the mixer filling height as the most important operational parameter in comparison with mixing time and impeller rotational speed. The present study investigated the effect of feed preparation characteristics (particle size and preblending) and operational parameters (rotational speed and mixing time) on mixing homogeneity in a convective batch ribbon mixer. A mixture of lactose, ascorbic acid, and zinc oxide was employed. Due to the different characteristics of the powders, it was assumed the mixture was heterogeneous.

\section{Materials and methods}

\section{Convective batch ribbon mixer}

The convective batch ribbon mixer used in this study was designed for a laboratory study (unpublished). This mixer is classified as a convective mixer and is comprised of a U-shaped container (length $30 \mathrm{~cm}$, height $12 \mathrm{~cm}$, width $10 \mathrm{~cm}$ ) that houses a horizontal ribbon mixer (length $40 \mathrm{~cm}$, diameter $9 \mathrm{~cm}$ ) with a double layer of spiral blades (Figure 1). This scaled-down mixer is made from poly(methyl methacrylate) and the blade and shaft are made from stainless steel. A motor (RW20; IKA GmbH, Königswinter, Germany) is used to provide rotational movement to the shaft. The rotation speeds range from 10 to $90 \mathrm{rpm}$. The powders are fed into and removed from the mixer through the detachable hinged top.

\section{Blend formulation}

Two model blends were formulated using ascorbic acid (25\%) (Northeast General Pharmaceutical Factory, Shenyang, China), zinc oxide (2.5\%) (Approfit Zinc Oxide Sdn Bhd, Puchong, Malaysia), and lactose (72.5\%) (DMV-Fonterra Excipients, Goch, Germany). The ratios of these powders were in accordance with the most common dosage of vitamin C supplement, in which the approximate amount of ascorbic acid in one tablet is $250 \mathrm{mg}$ (as the suggested dosage is $250 \mathrm{mg}$ per day). ${ }^{7}$ This basic formulation was used as a model blend, consisting of an active substance (ascorbic acid) and excipients (lactose and zinc oxide). Lactose acts as a binder while zinc oxide enhances the absorption of ascorbic acid by the human body. The properties of each powder were studied during a preliminary investigation (unpublished). Table 1 shows the properties of the materials. Figure 2 provides a scanning electron microscope micrograph of the materials.

\section{Feed preparation and mixing procedure}

Feed can be prepared with (1) preblending or (2) without preblending. For the preblend, $500 \mathrm{~g}$ of lactose was fed into the mixer. Then $225 \mathrm{~g}$ lactose and $25 \mathrm{~g}$ of zinc oxide were manually mixed together for 5 minutes in an enclosed container by imitating a tumble mixer movement. Then the lactose-zinc oxide mixture was similarly mixed manually with $250 \mathrm{~g}$ ascorbic acid. Finally, the preblend powder was fed into the mixer. For feed preparation 2 (not preblended), all the ascorbic acid, zinc oxide, and lactose were fed into the mixer simultaneously.

Mixing parameters employed in this study are described in Table 2. After the mixing process, a $100 \mathrm{~g}$ sample was collected at every twelve points within the mixer (Figure 3)

Table I Properties of the materials

\begin{tabular}{|c|c|c|c|c|}
\hline Properties & Ascorbic acid & Zinc oxide & Lactose I00M & Lactose $200 \mathrm{M}$ \\
\hline Mean particle size $(\mu \mathrm{m})$ & 126 & 7 & 118 & 49 \\
\hline Poured density $(\mathrm{g} / \mathrm{mL})$ & 0.85 & 0.58 & 0.73 & 0.54 \\
\hline Tapped density $(\mathrm{g} / \mathrm{mL})$ & 1.08 & 0.87 & 0.88 & 0.80 \\
\hline Hausner ratio & 1.27 & 1.5 & 1.21 & 1.47 \\
\hline Carr's index (\%) & 21 & 33 & 17 & 33 \\
\hline $\begin{array}{l}\text { Flowability } \\
\text { (Carr's index as reference }\end{array}$ & Fair & Poor & Fair & Poor \\
\hline Moisture content (\%) & 0.45 & 0.29 & 0.38 & 0.26 \\
\hline Morphology & $\begin{array}{l}\text { Irregular - nearly monoclinic } \\
\text { crystal structure }\end{array}$ & $\begin{array}{l}\text { Crystal structure - hexagonal } \\
\text { and cubic }\end{array}$ & Irregular & Irregular \\
\hline
\end{tabular}



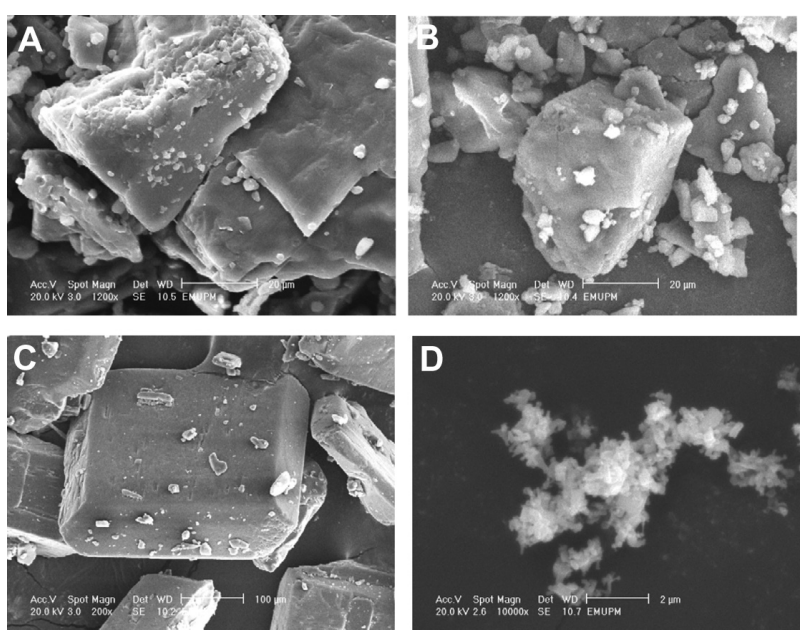

Figure 2 Scanning electron microscope micrographs: (A) lactose I00M at a magnification of $1200 \times$, (B) lactose 200 M at a magnification of $1200 \times$, (C) ascorbic acid at a magnification of $200 \times$, (D) zinc oxide at a magnification of $10000 \times$.

to ensure thorough characterization by considering areas that that may have different shear conditions. The selection of sampling positions was based on Muzzio et al. ${ }^{8}$ Three samples were withdrawn from each point. A core sampling technique was applied for obtaining three-dimensional sampling as it allows a cross-sectional sample to be taken from each sample location.

\section{Homogeneity measurement}

In this project, the effect of mixing parameters on the homogeneity of the output stream was determined by analyzing the output samples as a function of time. To analyze homogeneity, it is necessary to determine the amount of tracer (ascorbic acid) in the sample using chemical testing techniques. The mixture was tested by titrating the dissolved sample with redox-indicator solution, 2,6-diclorophenolindophenol (AOAC Method 967.21).

Prior to this, a standard was prepared to compare homogeneity. In this study the ascorbic acid powder consisted of approximately 97\% ascorbic acid and 3\% cellulose. This meant that $242.5 \mathrm{~g}$ of ascorbic acid was contained in $250 \mathrm{~g}$ of ascorbic acid powder. While, in $1000 \mathrm{~g}$ total quantity of mixture, the standard amount of ascorbic acid content in the

Table 2 Mixing parameters

\begin{tabular}{ll}
\hline Parameters & Description \\
\hline Mixer run time (minutes) & $5,10,15,20,25$ \\
Blade speed (rpm) & $40,60,80$ \\
Feed preparation & Preblend and without preblend \\
Filler-binder particle size & Lactose I00M $(1 \mathrm{I} 8 \mu \mathrm{m})$ \\
& Lactose $200 \mathrm{M}(49 \mu \mathrm{m})$ \\
\hline
\end{tabular}

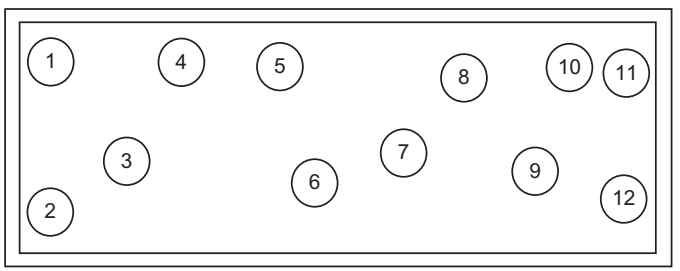

Figure 3 Upper view of convective batch ribbon mixer showing the twelve sampling positions.

mixture is $24.25 \%$. Therefore, $24.25 \%$ ascorbic acid content was set as the standard specification, with an acceptable range of $24.25 \% \pm 2.4 \%$. Samples that fell within this range automatically categorized as meeting the specification. Those samples that did not meet the specification were defined as nonhomogenous.

\section{Results and discussion}

Figure 4 illustrates the amount of ascorbic acid present at the different mixing times at the lowest rotational speed used in this work, $40 \mathrm{rpm}$. Longer mixing resulted in a more homogeneous mixture. The lactose 200M and lactose $100 \mathrm{M}$ mixtures with preblending were more likely to meet the specification, whereby after 15 minutes mixing, they have fulfilled the minimum homogeneity requirement. The repetition results for the mixture with preblending were similar. The powder particle size also affected the mixing performance. Lactose $100 \mathrm{M}$, having relatively larger particle size in comparison with lactose $200 \mathrm{M}$, exhibited poor homogeneity in the absence of a preblend. Lactose $200 \mathrm{M}$ without preblending had better homogeneity, and achieved the minimum homogeneity requirement after 20 minutes of mixing time. These trends are supported by the relatively small particle sizes (Table 1) and large apparent surface area

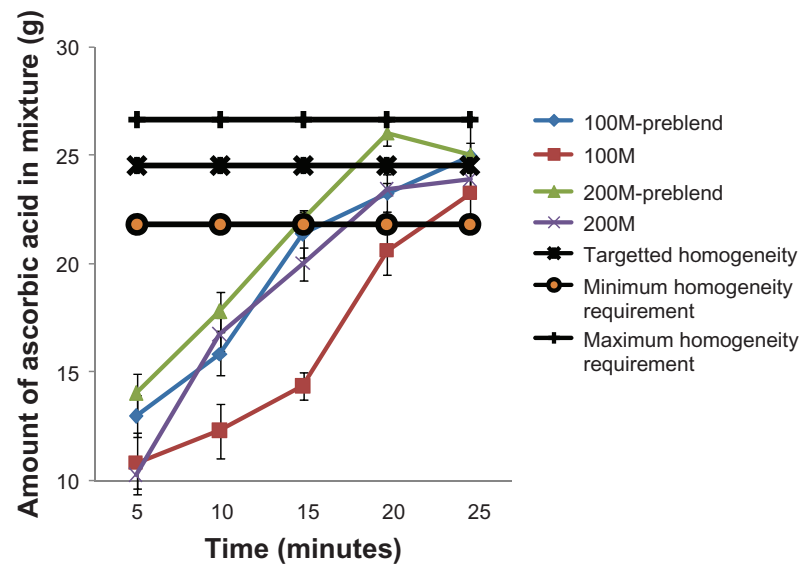

Figure 4 Ascorbic acid content in the mixture after mixing at $40 \mathrm{rpm}$. 
(Figure 2) of lactose 200M, which can adhere to the larger ascorbic acid particles thus minimizing segregation. The flowability of the powder may also be considered as a factor that affects the homogeneity of the mixture. Lactose 100M has better flowability than the Lactose 200M (Table 1). Due to the lack of mobility of lactose 200M, ascorbic acid tends to hold and lock lactose $200 \mathrm{M}$ inside the powder bed and thus produces an ordered mixture. Mixtures containing lactose $100 \mathrm{M}$ will need a longer period to achieve homogeneity as the particles are free to move and tend to segregate. All mixtures achieved the homogeneity requirement after a mixing time of 25 minutes at the lowest rotational rate of $40 \mathrm{rpm}$.

Figure 5 shows the amount of ascorbic acid present at the different mixing times at the medium rotational speed of $60 \mathrm{rpm}$. It is interesting to note that, at $60 \mathrm{rpm}$, all the mixtures achieved the required homogeneity in a shorter mixing time of 20 minutes. At the highest rotational speed used in this work, $80 \mathrm{rpm}$, all mixtures met the specification after 10 minutes of mixing (see Figure 6). However, the mixture containing lactose $200 \mathrm{M}$ without preblending showed particle segregation, and the homogeneity decreased below the minimum requirement. The high rotational rate provides high shear stresses and this breaks down agglomerates of cohesive powders. Comparative results are difficult to obtain at high shear stress mixing conditions. For instance, the results varied significantly (standard deviation varied between 2.8 and 4.2) for each repetition test at 5 minutes and at 25 minutes for the mixture containing lactose $100 \mathrm{M}$ without preblending. This error could also be due to the segregation effect. Thus, prolonged periods of high-speed mixing resulted in segregation.

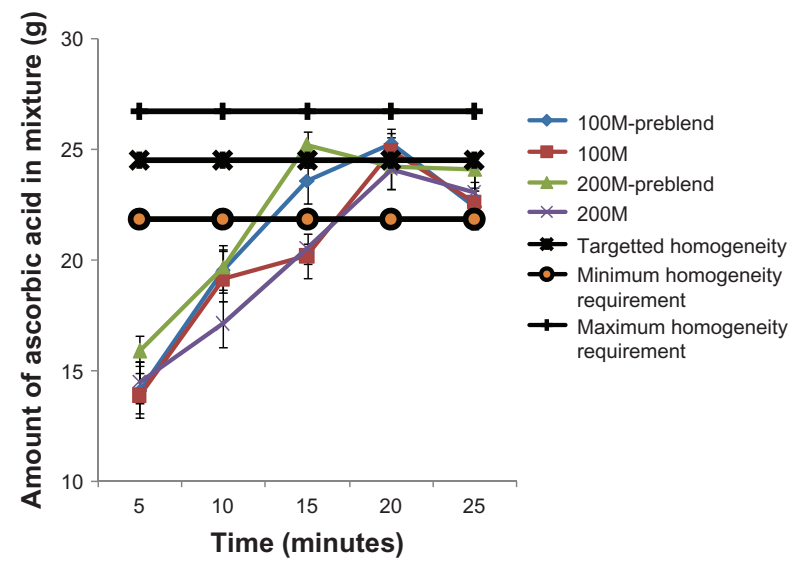

Figure 5 Ascorbic acid content in the mixture after mixing at $60 \mathrm{rpm}$.

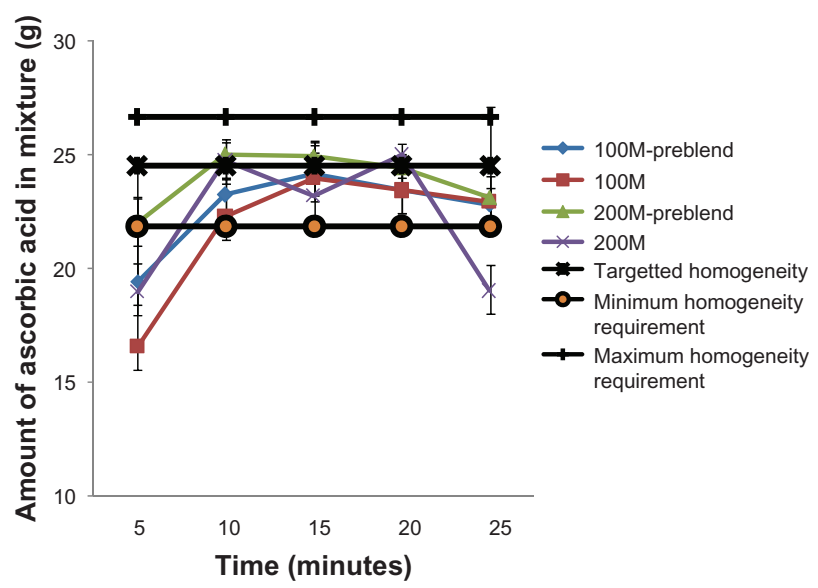

Figure 6 Ascorbic acid content in the mixture after mixing at $80 \mathrm{rpm}$.

\section{Conclusion}

It was found that mixtures containing lactose $200 \mathrm{M}$ with preblending always met the specification with the shortest mixing time. These results illustrate that using binders with a smaller particle size and using a preblending technique improves the mixing process in a convective batch ribbon powder mixer. As the particle size becomes smaller, the contact surface of each particle will increase, thus promoting agglomeration of the different particles within the mixture. However, prolonged periods of high-speed mixing will lead to mixture segregation. This phenomenon could be seen at $80 \mathrm{rpm}$ for lactose $200 \mathrm{M}$ without preblending.

\section{Acknowledgment}

The support of the Ministry of Higher Learning Malaysia through FRGS grant (5523395) is acknowledged. The authors would also like to thank Approfit Zinc Oxide Manufacturing Sdn Bhd, Puchong, Malaysia, for providing the zinc oxide powder.

\section{Disclosure}

The authors report no conflicts of interest in this work.

\section{References}

1. Bridson RH, Robbins PT, Chen Y, et al. The effects of high shear blending on alpha-lactose monohydrate. Int J Pharm. 2007;339(1-2):84-90.

2. Portillo PM, Ierapetritou MG, Muzzio FJ. Effects of rotation rate, mixing angle, and cohesion in two continuous powder Mixers-A statistical approach. Powder Technology. 2009;194(3):217-227.

3. Marikh K, Berthiaux H, Mizonov V, Barantseva E. Experimental study of the stirring conditions taking place in a pilot plant continuous mixer of particulate solids. Powder Technology. 2005;157(1-3):138-143.

4. Portillo PM, Ierapetritou MG, Muzzio FJ. Characterization of continuous convective powder mixing processes. Powder Technology. 2008;182(3):368-378. 
5. Muzzio FJ, Shinbrot T, Glasser BJ. Powder technology in the pharmaceutical industry: the need to catch up fast. Powder Technology. 2002;124(1-2):1-7.

6. Côté P, Abatzoglou N. Powder and other divided solids mixing. Scale-up and parametric study of a ribbon blender used in pharmaceutical powders mixing. Pharm Dev Technol. 2006;11(1):29-45.

7. Fortitech. Vitamin C. Strategic Nutrition [homepage on the Internet]. New York: Fortitech, Inc. [Updated 2006.]. Available from: http://www. fortitech.com/default.aspx?NHIObjectID=100078\&TabID=72. Accessed October 18, 2011.
8. Muzzio FJ, Llusa M, Goodridge CL, Duong N, Shen E. Evaluating the mixing performance of a ribbon blender. Powder Technology. 2008; 186:247-254.

\section{Publish your work in this journal}

Drug Design, Development and Therapy is an international, peerreviewed open-access journal that spans the spectrum of drug design and development through to clinical applications. Clinical outcomes, patient safety, and programs for the development and effective, safe, and sustained use of medicines are a feature of the journal, which has also been accepted for indexing on PubMed Central. The manuscript management system is completely online and includes a very quick and fair peer-review system, which is all easy to use. Visit http://www.dovepress.com/testimonials.php to read real quotes from published authors.

Submit your manuscript here: http://www.dovepress.com/drug-design-development-and-therapy-journal 